\title{
EDUCACION, FORMACION PROFESIONAL Y EMPLEO: EL SECTOR INDUSTRIAL EN COLOMBIA, 1981*
}

En qué medida el sector empresarial tiene en cuenta el nivel educativo y la formación profesional en el reclutamiento de personal a cargos técnicos?

Qué tanta variabilidad tiene el perfil y las condiciones de trabajo de los técnicos de una empresa a otra?

Están los egresados de la educación técnica ocupando cargos para los cuales se han formado?

Respuestas a estos y otros interrogantes son las que pretende dar este estudio, realizado entre 230 empresas del sector industrial moderno, ubicados en ocho áreas metropolitanas: Bogotá-Soacha; Medellín-Valle de Aburrá; Manizales Villamaría; Barranquilla-Soledad; Pereira-Santa Rosa, Dosquebradas y Cartagena.

Se seleccionaron y encuestaron un total de 2.355 personas entre profesionales, técnicos, bachilleres técnicos y obreros calificados ubicados en distintos puntos de trabajo dentro de la empresa y que proporcionaron información, entre otros aspectos, sobre las estructuras ocupacionales y criterios de reclutamiento para los cargos de profesionales, técnicos y obreros calificados; perfiles educativos y profesionales y niveles de remuneración.

El capítulo primero analiza la influencia que sobre las estructuras ocupacionales y sobre la utilización de los recursos humanos tienen variables tales como tipo de actividad de la empresa, proceso de producción utilizado, capital social, tamaño de la empresa, región de influencia, amplitud de su clientela, organización jurídica y grado de participación sindical de los empleados.

El capítulo segundo estudia los criterios utilizados por las empresas en el reclutamiento de personal para los diversos cargos y analiza el perfil de los empleados según sexo, edad, orígenes geográficos y sociales, nivel educativo, experiencia y formación profesional y finalmente, examina la política de formación de las empresas.

El capítulo tercero analiza el funcionamiento del mercado de trabajo y las variaciones existentes entre los diversos salarios y los factores que las explican.

El capítulo cuarto hace consideraciones sobre la eficacia de los diversos tipos de formación técnica industrial, partiendo de los resultados de la investigación.

\section{FINANCIAMIENTO DE LA EDUCACION, 1980*}

La planificación, programación y administración presupuestaria de la educación exige de una permanente y actualizada información que permita el conocimiento oportuno y ágil de la situación económico-financiera de los Fondos Educativos Regionales-FER. Con el fin de satisfacer estos requerimientos, se diseñó este estudio que aporta una infraestructura de información consistente en dos tipos de cuadros modelos.

\footnotetext{
* Investigación realizada por Francoise Caillods y Guillermo Briones.

* Preparado por Jorge Quintana Vargas.

Digitalizado por RED ACADEMICA
} 
1. Cuadros de fuentes y usos de fondos que permiten visualizar cómo los diversos aportes se distribuyen en los distintos programas educativos, excluyendo el nivel universitario. Se elaboraron cuadros por cada FER (33 en total) y cuadros resúmenes que agrupan Departamentos, Intendencias, Comisarías y la Nación en general.

2. Cuadros adicionales de análisis que permiten visualizar aspectos tales como la composición del financiamiento de los FER, distribución del gasto total por programas y tipos de gastos según divisiones seccionales, composición porcentual del financiamiento de cada programa y de sus respectivos objetos del gasto y distribución porcentual de cada fuente de financiamiento por programas y objetos del gasto.

Como información básica se utilizó la proporcionada por los informes de ejecución presupuestal de 1979. 